\title{
Assessment of exposure to workplace violence and related factors in nurses of teaching hospitals affiliated to Kurdistan University of Medical Sciences, 2016
}

Abdorrahim Afkhamzadeh ${ }^{1}$, Obeidollah Faraji ${ }^{2}$

1.Associate Professor, Social Determinants of Health Research Center, Research Institute for Health Development, Kurdistan University of Medical Sciences, Sanandaj, Iran. ORCID ID: 0000-0003-4496-2466

2. Assistant Professor, Social Determinants of Health Research Center, Research Institute for Health Development, Kurdistan University of Medical Sciences, Sanandaj, Iran., (Corresponding Author), Tel: 087-33664645, Email: faraji.obeid@gmail.com, ORCID ID: 0000-0003-2415-3370

\begin{abstract}
Background and Aim: Violence in the hospital is a common phenomenon. Among the hospital staff, nurses are at greater risk of exposure to violence. The purpose of this study was to investigate the exposure to workplace violence in nurses and its related factors.

Materials and Methods: This descriptive-analytical study included 309 nurses working in the teaching hospitals affiliated with Kurdistan University of Medical Sciences in 2016. We collected data using a modified workplace violence questionnaire. Chi-square and Fisher's exact tests were used for data analysis. A $P$-value of less than $5 \%$ was considered significant.

Results: The results showed that the most a frequent type of violence was verbal (79\%). Also exposure to physical violence had statistically significant relationships with age, sex, marital status, work experience and working hours $(\mathrm{P}<0.05)$. There was also a statistically significant relationship between age and inpatient ward with verbal violence and also between age, sex, work experience, and inpatient ward with bullying $(\mathrm{P}<0.05)$.

Conclusion: The results showed that nurses' exposure to workplace violence was high and the risk of exposure to violence decreased with age and higher work experience. Therefore, measures such as training courses on proper communication with patients and colleagues and improvement of coping skills for stressful and violent situations are recommended.
\end{abstract}

Keywords: Nurses, Workplace violence, Teaching hospital, Kurdistan

Received: June 19, $2019 \quad$ Accepted: July 9, 2019

How to cite the article: Abdorrahim Afkhamzadeh, Obeidollah Faraji. Assessment of Exposure to Workplace Violence and Related Factors in Nurses of Teaching Hospitals Affiliated to Kurdistan University of Medical Sciences, 2016. SJKU. 2020;25(5):113-122.

Copyright (C) 2018 the Author (s). Published by Kurdistan University of Medical Sciences. This is an open access article distributed under the terms of the Creative Commons Attribution-Non Commercial License 4.0 (CCBYNC), where it is permissible to download, share, remix, transform, and buildup the work provided it is properly cited. The work cannot be used commercially without permission from the journal 


\section{ارزيابى مواجهه با خشونت محلكار و عوامل مرتبط با آن در برستاران بيمار ستانهاى آموزشى

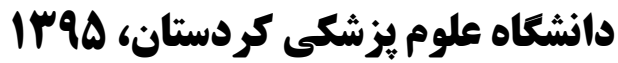

عبدالرحيم افخم زاده'، عبيداله فرجىى

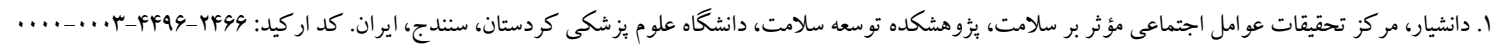

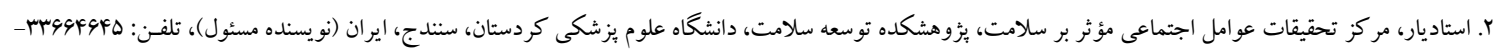

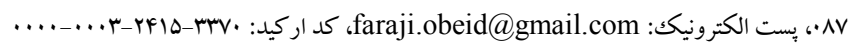

جִكيله زمينه و هدف: در ميان كار كنان بيمارستان، برستاران در معرض خطر مواجهه با خشونت بيشترى نسبت به ساير كار كنان هستند.

$$
\text { هدف از اين مطالعه تعيين مواجهه با خشونت محل كار و عوامل مرتبط با آن در پيرستاران بود. }
$$
مواد و روش ها: اين يزوهش يكك مطالعه توصيفى تحليلى بود كه بر روى ه.r نفر از برستاران بيمارستانهاى آموزشى دانشگاه علوم يزشكى كردستان در سال ههبا انجام شد. ابزار جمع آورى دادهها يرسشنامه تعديلشده خشونت محل كار در محيطهاى بهداشتى بود. در تجزيهوتحليل اطلاعات از آزمونهاى كاى دو و تست دقيق فيشر استفاده گرديد. P-value كمتر از ه درصد به عنوان سطح معنى دارى در نظر كرفته شد. يافته ها: نتايج نشان داد بيشتر ين نوع مواجهه با خشونت، كلامى (V9 درصد) بوده است. همجنين نتايج مطالعه نشان داد كه ارتباط آمارى معنىدارى بين سن، جنسيت، وضعيت تأهل، سابقه كارى و بخش كارى و شب كارى با مواجهه با خشونت فيزيكى وجود دارد (ه •/P>P). همجنين بين سن و بخش كارى با خشونت كلامى و بين سن، جنسيت، سابقه كارى و بخش كارى با زوركويى رابطه آمارى معنى دار وجود دارد (ه) (P> (P). نتيجه كيرى: نتايج اين مطالعه نشان داد كه ميزان مواجهه برستاران با خشونت در محل كارشان بالا است و با افزايش سن و سابقه كارى ميزان مواجهه با خشونت كاهش مىيابد. لذا اقداماتى مانند بر گزارى دورههاى آموزشى در زمينه برقرارى ارتباط مناسب با بيماران و همكاران و ارتقاى مهارتهاى برخورد با شرايط تنشزا و خشونت آفرين بخصوص براى برستاران جوانتر و با سابقه

$$
\text { كمتر بيشنهاد مى شود. }
$$

كلمات كليدى: برستاران، خشونت محل كار، بيمارستان آموزشى، كردستان

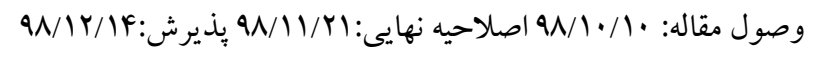


مشكلات جسمى و روانى براى برستاران مىشود و در نتيجه مى تو اند سطح عملكرد، بهرهورى، كيفيت خدمت و رضايت شغلى آنها را كاهش و سبب افرايش خطاهاى بزشكى و

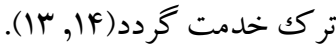

عوامل خطر مختلفى مرتبط با مواجهه با خشونت در برستاران در مطالعات مختلف ذكر شده است از قبيل بخش مأش

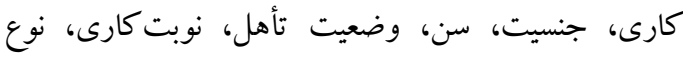

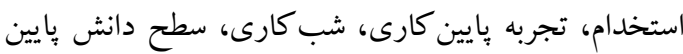

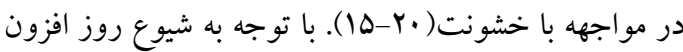
ميزان مواجهه با خشونت در برستاران در كشورهاى مختلف

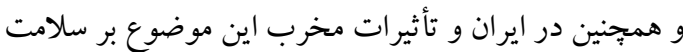
جسمى و روانى آنان و همجنين افزايش هزينههاى بيمارستان

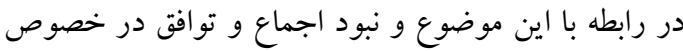

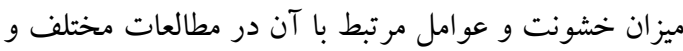
اختلاف در ميزان مواجهه با خشونت در محيط بيمارستانى

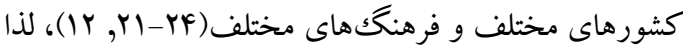

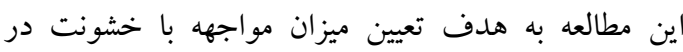
يرستاران و عوامل مرتبط با آن در بيمارستانهاى آموزشى لئس

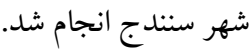

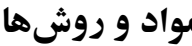

اين يزوهش يكك مطالعه توصيفى تحليلى بود كه بر روى

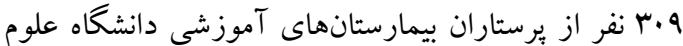
يزّشكى كردستان در سال هوها انجام شد. حجم نمونه در اين مطالعه با توجه به شيوع خشونت (VY/D درصد)، بر اساس فاصله اطمينان هذ٪ و ه.٪ خطاى معيار قابل قبول برابر צاM نفر برآورد گرديد كه q.r نفر در مطالعه شركت

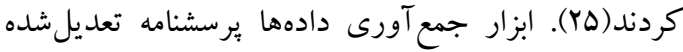
خشونت محل كار در محيطهاى بهداشتى بركرفته از يرسشنامهاى جامع و استاندارد بود كه با همكارى سازمان بهان جهانى كار، سازمان بهداشت جهانى، انجمن بين المللى

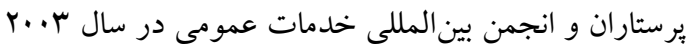
تدوين شده بود(Y) كه با ايجاد تغييراتى براى بررسى
مقدمه خشونت در محل كار (Workplace Violence) بديده شايعى است. كار كنان بيمارستان همانند ساير كاركنان در معرض مواجهه با خشونت در محل كار هستند(1). بر طبق

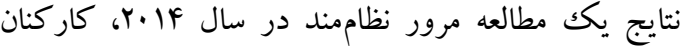
نظام سلامت نسبت به ساير كاركنان در معرض بيشترين خطر مواجهه با خشونت در محل كار هستند(1). در ميان كار كنان بيمارستان نيز يرستاران در معرض خطر مواجها لهانه بال خشونت بيشترى نسبت به ساير كاركنان هستند كه اين به دليل تماس مستقيم برستاران با بيماران و خانو ادههايشان و لئر همجِين كذراندن تعداد ساعات زياد با بيماران مىباشد(זّ, .$(r$ خشونت در محل كار به صورت "هر گونه اعمال خشونت يا تهديد به انجام آن در محل كار و در حين انجام وظيفه كه منجر به زيان جسمى يا عاطفى به كار كنان مىشود" تعريف

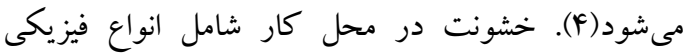
(Physical)، كلامى (Verbal)، زور گويى (Bullying) و جنسى (Sexual) مىباشد(ه). بر طبق مطالعات قبلى بيشترين نوع خشونت تجربهشه توسط برستاران كلامى و عاطفى و بس باز آن به ترتيب فيزيكى و جنسى بوده است (V, و $).$ مطالعات مختلف در دنيا از جمله در تركيه و برزيل حاكى از آن است كه ميزان شيوع مواجهه با خشونت در برستاران بين rV درصد تا ..1 درصد مىباشد(q, A). همجينين مطالعاتى نشان دادهاند كه ميزان مواجهه با خشونت در كشورهاى خاورميانه بيش از ساير نقاط دنيا و حدود درصد مىباشد( ||--1, ه). در مطالعه مرور نظاممندى در

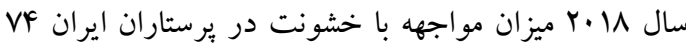

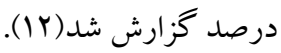
اثرات مخرب خشونت در محل كار را مىتوان به اثرات

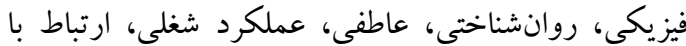
بيماران و كيفيت مراقبت، اجتماعى و مالى تقسيم كرد(1). خشونت در محل كار باعث كاهش روحيه كاركنان، از دست دادن اعتماد، فرسودگى شغلى (Job Exhaustion)، 
خشونت فيزيكى، كلامى و زورگويى را تجربه كردهاند

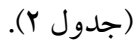
همجنين نتايج مطالعه نشان داد كه ارتباط آمارى معنىدارى ميان سن، جنسيت و وضعيت تأهل، سابقه كارى و بخش محل كار و شيفت شب كارى با مواجهه با خشونت فيزيكى

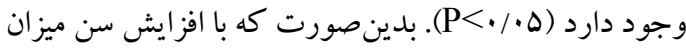

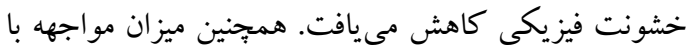
خشونت فيزيكى در مردان بالاتر از اين ميزان در زنان بود. علاوه بر اين، افراد مجرد، افراد با سابقهارى كمتر و يرستاران شاغل در شيفت شب و إِرستاران بخش روانيزشكى نسبت به ساير افراد مواجهه با خشونت بيشترى داشتند. همجنين ميان سن و بخشكارى با خشونت كلامى لئى رابطه آمارى معنى دار وجود داشت (ه •/P<). بدينصورت كه افراد با سن بايينتر و ورستاران شاغل در بخشهاى اورزانس و روانيزشكى در مقايسه با ساير يرستاران ميزان مواجهه با خشونت بيشترى را تجربه كرده بودند. همجنين ميان سن، جنسيت، سابقه كارى و بخش كارى با زوركويى رابطه آمارى معنى دار وجود داشت (ه •/P<). بدين صورت كه افراد با سن بايينتر نسبت به افراد با سن بالاتر، مردان نسبت به زنان، افراد با سابقه كارى پايينتر نسبت به افراد با باد

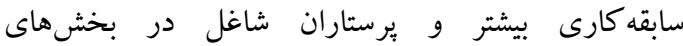
روانيزشكى و مراقبتهاى ويزه نسبت به برستاران ساير بخشها، مواجهه بيشترى با خشونت محل كار داشتند

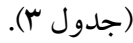

مو اجهه با خشونت در برستاران استفاده شد. برسشنامه داراى دو قسمت است. قسمت اول ويزگگ هاى فردى و سازمانى يرستاران شامل سن، جنسيت، وضعيت تأهل، تحصيلات، قوميت، وضعيت استخدام، سابقه كارى، شب كارى، بخش كارى و تعداد كار كنان بخش را مىسنجد و در قسمت دوم شيوع انواع مختلف خشونت محل كار عليه برستاران و علل

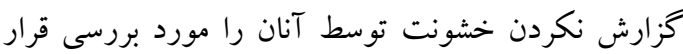
مىدهد. روايى صورى و محتواى يرسشنامه با استفاده از روايى محتوا توسط نظرخواهى از لـ انفر از اساتيد دانشكاه علوم يزشكى كردستان بررسى شد و مورد تائيد قرار كرفت. CVR و CVI براى سؤ الات اين برسشنامه به تر برتيب

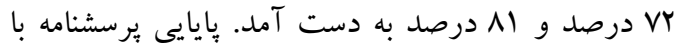
روش باز آزمايى بر روى ·r برستار انجام شد. در اين

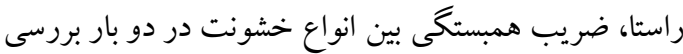
تعيين شد. اين ضريب در مورد انواع مختلف خشونت

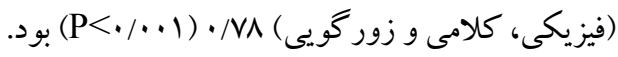

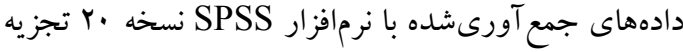
وتحليل شدند. در تجزيهوتحليل اطلاعات از آزمونهاى كاى دو و تست دقيق فيشر استفاده گرديد. P-value كمتر از هـ به عنوان سطح معنىدارى در نظر گرفته شد. علاوه بر اينكه طرح به تصويب كميته اخلاق بززوهش دانشكاه علوم يُزشكى كردستان (IR.MUK.REC.1393.16) گرديد، در تمامى مراحل كار ملاحظات اخلاقى از قبيل كسب مجوزهاى لازم، گرفتن رضايت كتبى جهت ورود به مطالعه ماله و محرمانه ماندن اطلاعات رعايت شد.

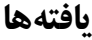

در اين بثزوهش بيشتر افراد مورد مطالعه خانم، متأهل، كارشناس، داراى سابقه كارى كمتر از ه سال و شبكار بودند (جدول (). نتايج نشان داد كه هY درصد، VQ Vورصد و

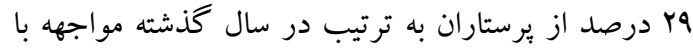




\begin{tabular}{|c|c|c|c|}
\hline \multirow{2}{*}{ درصد } & \multirow{2}{*}{ تعداد } & \multicolumn{2}{|c|}{ متغيرها } \\
\hline & & $<r$. & سن \\
\hline FF & ird & $\boldsymbol{r} \cdot-r$. & \\
\hline 9 & rq & $>r$. & \\
\hline 99 & (M & 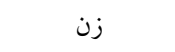 & جنسيت \\
\hline rI & 99 & مرد ل & \\
\hline f. & 1Y9 & مجرد & وضعيت تأهل \\
\hline 4. & M & متأهل & \\
\hline १४ & $r \cdot 1$ & كارشناس & مدر كى تحصيلى \\
\hline r & $\wedge$ & كاردان & \\
\hline er & ir. & $<\Delta$ & سابقه كار (سال) \\
\hline 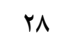 & $\wedge \vee$ & $\Delta-1$. & \\
\hline 10 & pV & $11-10$ & \\
\hline 10 & Fo & $<10$ & \\
\hline YF & vo & داخلى & بخش بيمارستان \\
\hline 9 & rq & جراحى & \\
\hline if & FF & اورزانس & \\
\hline YF & vo & مر اقبت هاى ويثزه & \\
\hline ir & ra & روانيزشكى & \\
\hline 19 & $\Delta$. & ساير بخشها & \\
\hline vi & YMI & بله & شب كارى \\
\hline rq & $M$ & خير & \\
\hline
\end{tabular}

\begin{tabular}{|c|c|c|c|c|c|c|c|}
\hline \multicolumn{2}{|c|}{ زورگويى } & \multicolumn{2}{|c|}{ خشونت كلامى } & \multicolumn{2}{|c|}{ خشونت فيزيكى } & & \\
\hline درصد & تعداد & درصد & تعداد & درصد & تعداد & & \\
\hline rq & 91 & va & TFD & ro & $\mathrm{v \Lambda}$ & بله & \\
\hline vi & YMA & rI & $q 4$ & VD & TrI & خير & مواجهه با خشونت \\
\hline $1 \ldots$ & $r . q$ & $1 \ldots$ & $r \cdot q$ & $1 \ldots$ & $r . q$ & جمع & \\
\hline
\end{tabular}




\begin{tabular}{|c|c|c|c|c|c|c|c|c|c|c|}
\hline & & نت & هله با & ميزان & ـ و سازمانح & هاى فر & لـ بين متغي & ول r. ار & & \\
\hline $\mathbf{D}$ & كويى & زور & $\mathbf{D}$ & كلامى & خشونت & D & فيزيكى & خشونت & & متغيرها \\
\hline $\mathbf{r}$ & خير & بله & 1 & خير & بله & $\mathbf{F}$ & خير & بله & & \\
\hline & تعداد (\%) & تعداد(\%) & & تعداد(\%) & تعداد(\%) & & تعداد(\%) & تعداد(\%) & & \\
\hline & $(r \Delta / Y)) \cdot q$ & $(1 \cdot / V) H F$ & & $(11 / \Delta)+4$ & $(r \Delta / Y) 1 \cdot q$ & & $(\Gamma / T) 1.9$ & $(1+/ 9) r q$ & $r \cdot>$ & سن (سال) \\
\hline$<\cdot / \cdot \cdot 1$ & $(r q) q$. & $(\mid F / F) F \Delta$ & $<\cdot / \cdot \cdot 1$ & (V)YY & r & ./.r & $(r Y / Q)) \cdot Y$ & سח(19.19) & $f \cdot-r$. & \\
\hline & $(\Delta / \Delta) r$. & $(Y / 9) 9$ & & $(Y) 9$ & r/F)r & & $(9 / 0) r r$ & $(1 / 9) 9$ & f. $<$ & \\
\hline & $(\Delta \mid / F) \backslash \Delta q$ & $(I V / F) \Delta F$ & & $(\mid F / \Lambda) \& G$ & $(\Delta F) \backslash G V$ & & $(\Delta \Lambda / \Delta) \backslash \Lambda\rangle$ & $(1 \cdot / r) H r$ & زن & جنسيت \\
\hline.$/ . r$ & $(19 / 4) q$ & $(11 / 9)+4$ & $\cdot / \Delta 9 \Lambda$ & $(\Delta / \wedge) \backslash \wedge$ & $(Y \Delta / Y) V \wedge$ & $<\cdot / \cdot \cdot 1$ & $(19 / 1) \Delta$. & $(\mid F / q) \& G$ & مرد & \\
\hline & $(Y Q / \Delta) q 1$ & $(\mid r / Y) F \mid$ & & $(\Lambda / V) Y V$ & $(r F) 1 \cdot \Delta$ & & $(Y \wedge / \Delta) M$ & $(\mid F / Y) F F$ & مجرد & وضعيت \\
\hline$\cdot / \mu F$ & $(F \mid / F) \mid r \wedge$ & $(1 \Delta / \Lambda) \& q$ & $\cdot 19 \Delta \mathrm{V}$ & $(11 / 9) \mathrm{rV}$ & $(F \Delta) \backslash F$. & $.1+9$ & $(F q / Y) \mid k r$ & $(11)^{r k}$ & متأهل & تأهل \\
\hline & $(9 N / Y) Y \|$ & $(r q / 1) q$. & & $(r \cdot / V) g F$ & $(V G / 9) Y M V$ & & (VY/I)Yr & $(Y \Delta / Y) V \Lambda$ & كارشناس & مدر كى \\
\hline .1 .94 & & &.$/ \mathrm{FT}$ & & & .1 .99 & & & & تحصيلي \\
\hline & $(Y / 9) \Lambda$ & $(\cdot)$. & & $(\cdot)$. & $(Y / \varphi) \Lambda$ & & $(Y / 9) \wedge$ & $(\cdot)$. & كاردان & \\
\hline & $(r Y / r)) \ldots$ & $(9 / \mathrm{V}) \mathrm{r}$ & & ه & $(r \cdot / V) 9 \Delta$ & & $(Y \Lambda / F) M$ & $(I T / \Delta) F Y$ & $\Delta>$ & سابقه- \\
\hline$<\cdot / \cdot \cdot \mid$ & $(Y, / T) 99$ & $(9 / \Lambda) Y I$ & $\cdot / \cdot \Delta \Delta$ & $(F / \Delta) \backslash F$ & $(Y r / 9) V r$ & $<\cdot / ., \mid$ & $(19 / 4) q$ & $(\Lambda / V) Y V$ & $\Delta-1$. & كار (سال) \\
\hline & $(V / F) r r$ & $(V / A) Y F$ & & $(1 / 9) 9$ & $(\mid r / r) \& \mid$ & & $(\mid F / Y) F F$ & (1)r & $11-10$ & \\
\hline & $(9 / v) r$. & $(\mathcal{F} / \Lambda) 10$ & & $(Y / 9) 9$ & $(11 / v)+4$ & & $(1 Y / q) r q$ & $(1 / 9) 9$ & $10<$ & \\
\hline & $(1 \Delta / \Delta) \& \Lambda$ & $(\Lambda / \mathrm{V}) \mathrm{rV}$ & & $(r / q) \backslash r$ & $(Y \cdot / F) G T$ & & $(19 / 4) 9$ & $(F / \Lambda) \backslash \Delta$ & داخلى & بخش \\
\hline.$/ \cdot 1$ & $(\varepsilon / f) r$. & $(1 / 9) 9$ & $<\cdot / \cdot \cdot \mid$ & $(r / \Delta) \backslash 1$ & $(F / \Lambda) \backslash \Delta$ & $<\cdot / \cdot . \cdot \mid$ & $(\Delta / \Delta) \mid V$ & $(Y / 9) q$ & جراحى & \\
\hline & $(\mid r / \Gamma) \Gamma$ & $(1 / 9) 9$ & & $(\cdot) \cdot$ & $(\mid F / T) F F$ & & $(\Lambda / 4) Y q$ & $(\Delta / \wedge) \backslash \Lambda$ & اورثانس & \\
\hline & $(I V / F) \Delta F$ & $(G / \Lambda) Y \mid$ & & $(\Delta / \wedge) \backslash \wedge$ & $(\mid N / \Delta) \Delta V$ & & $(Y \mu / Y) 99$ & $(1 / 9) 9$ & مراقبت هاى & \\
\hline & & & & & & & & & ويزٔه & \\
\hline & $(9 / v) r$. & $(Y / 9) 9$ & & $(r / q) \| r$ & $(\Lambda / V) r V$ & & $(\boldsymbol{F} / \Lambda) \backslash \Delta$ & $(V / V) Y F$ & روانيزشكى & \\
\hline & $(q / r) r q$ & $(V) Y I$ & & $(r / 9) 11$ & $(1 Y / 9) r q$ & & $(\mid F / I) F F$ & $(Y) \varphi$ & ساير & \\
\hline & $(\Delta / / 1) \backslash \Delta \Lambda$ & $(Y \cdot / \mu) \mathscr{T}$ & & $(1 Q / \Lambda) \& q$ & $(\Delta \Delta / 9) I V Y$ & & $(\Delta \cdot / 1) 1 \Delta \Delta$ & $(Y 1 / Y) 94$ & بله & شب كارى \\
\hline$\cdot / V \cdot F$ & $(19 / \mathrm{V}) 91$ & $(\Lambda / V) Y V$ & $\cdot / 419$ & $(\mathcal{F} / \Lambda) \backslash \Delta$ & $(Y \mu / \varphi) V r$ & $\cdot / \cdot r$ & $(Y F / G) V G$ & $(r / \Lambda) \mid r$ & خير & \\
\hline
\end{tabular}


بيماران مرد ارتباط دارند و خود اين مسئله مىتواند احتمال مواجهه با خشونت را افزايش دهد از طرفى ديخر مسائل فرهنكى از قبيل رعايت بيشتر حريم شخصى در برخورد با فال

زنان در جامعه ما مى تواند بر اين قضيه تأثير گذار باشد. نتايج مطالعه رابطه آمارى معنىدارى ميان سابقه كارى مواجهه با خشونت فيزيكى را نشان داد، طورى كه يرستارانى كه سابقه كارى بايين ترى داشتند در مقايسه با ساير برستاران مواجهه بيشترى با خشونت داشتند. مطالعات Zhang و همكاران (Y.IV) نتايج مشابه اين مطالعه را گزارش كردند، اما نتيجه مطالعه على يور و همكاران (IrqV) نشان داد كه ارتباطى ميان سابقه كارى و مواجهه با خشونت محل كار وجود ندارد(هr).

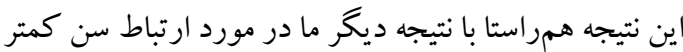
با ميزان مواجهه با خشونت در محل كار مىباشد. سن كمتر مى تواند به معنى سابقه كمتر و درنتيجه تجربه كارى كمتر و امكان كسب آموزشهاى كمتر در خصوص مديريت احساسات و برخورد با موقعيتهاى بحرانى و استرسزا و درنتيجه مواجها بيشتر با خشونت محل كار باشد.

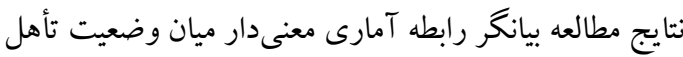
و مواجهه با خشونت فيزيكى بود كه اين نتيجه همسو با نتيجه مطالعه صلواتى و همكاران (Tوسا)(IV) بود، طورى كه آنه

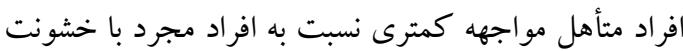
داشتند. شايد نتوان دليل موجهى براى اين رابطه بيان كرد

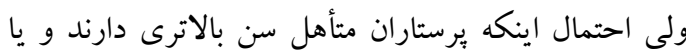
اينكه در مديريت احساسات خويش بهتر عمل مى كنند

$$
\text { مى تواند توجيه كننده اين رابطه باشد. }
$$
نتايج مطالعه ما نشاندهنده رابطه آمارى معنىدار لـار ميان شب كارى و مواجهه با خشونت فيزيكى بود كه همراستا با مانس

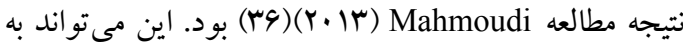
دليل كمتر بودن تعداد برستاران در شيفت شب و احتمال اورزانسىتر بودن بيماران در شب نسبت به روز و همجنين

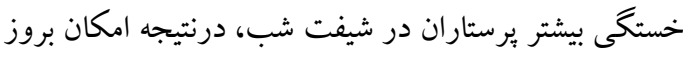
خشونت بيشتر از طرف بيماران و همراهان آنان باشد.
نتايج مطالعه نشان داد كه از ميان انواع خشونت محل كار، بشترين مواجهه يرستاران با خشونت كلامى (V9 درصد) بوده است كه اين نتايج همراستا با مطالعه Albashtawy و

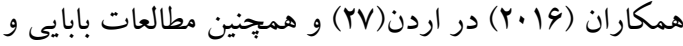

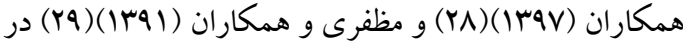
ايران مىباشد. بروز بالاتر خشونت كلامى تا حد زيادى قابل انتظار است زيرا بسيارى از افراد بهمض بران برانخيخته شدن،

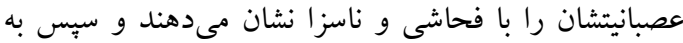
ساير انواع خشونت ماند تهلديد و خشونت فيزيكى روى مى آورند. در اين مطالعه مواجهه با خشونت فيزيكى از ميان انواع خشونت كمترين درصد را داشت كه مىتواند به دلايل فرهنكى و ترس از عواقب احتمالى از بيان و گزارش آن

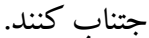
بر مبناى نتايج مطالعه ميان سن و انواع خشونت رابطه آمارى معنىدار و معكوس وجود داشت و با افزايش سن ميزان مواجهه با خشونت كاهش يافته است. اين نتيجه همراستا با

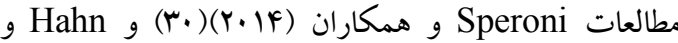

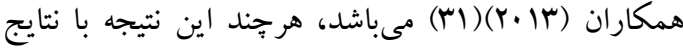
مطالعه مظفرى و همكارش (YqY I) متناقض بود (Yq). ارتباط سن بايين تر يرستاران با مو اجهه با خشونت محل كار مىتواند به دليل تجربه كمتر اين افراد در برخورد با شرايط كارى استرسزا و عدم توانيى كافى در ويشگيرى و مديريت موقعيتهاى خشونتآفرين و همجنين تمايل افراد جوانتر

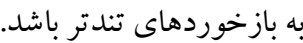
همجنين جنسيت با مواجهه با خشونت فيزيكى رابطه آمارى معنى دار داشت. طورى كه مردان مواجهه بيشترى با خشونت

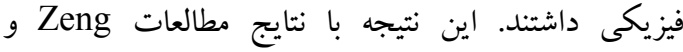

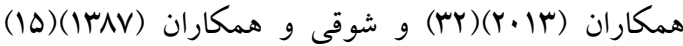
همخوانى دارد. ولى در مطالعه آقاجانلو و همكاران

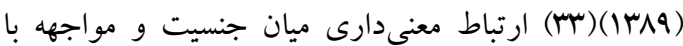
خشونت فيزيكى مشاهده نشد. دليل مواجهه بيشتر مردان با خشونت فيزيكى اين مىتواند باشد كه برستاران مرد با فرانيا 
مداخلات بيشگيرانه جهت كاهش خشونت در محل كار

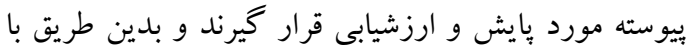
يافتن نقاط ضعف و كاستىهاى جنين برنامهايى در جهت

$$
\text { رفع و اصلاح آنها تلاش شود. }
$$

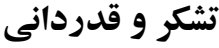

محققان بر خود لازم مىدانند از معاونت محترم تحقيقات و

فناورى دانشگاه علوم بز شكى كردستان به خاطر حمايت

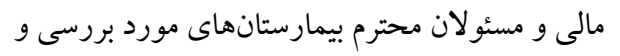

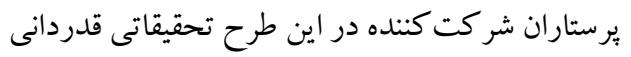

نمايند(كد طرح: IR.MUK.1393.16.
همجِنين نتيجه مطالعه نشاندهنده ارتباط آمارى معنىدار ميان بخش كارى و مواجهه با خشونت فيزيكى بود طورى كه يرستاران بخشهاى روانيزشكى و اورزانس نسبت به ساير

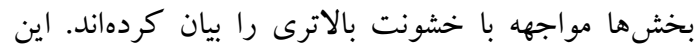
نتيجه همراستا با نتيجه مطالعه صلواتى و همكاران (IV)(بود. دلايل احتمالى براى توجيه اين رابطه مىتواند مواردى مانند نوع بيمارى در اين بخشها، تعداد

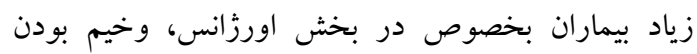
وضعيت بيماران در اكثر موارد در اين بخشها و استرس لهر بالاى آنان نسبت به ساير بخشها و تعداد كم كاركنان

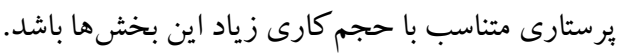

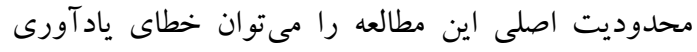

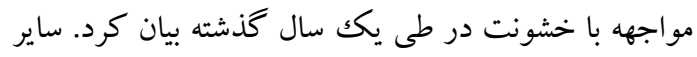

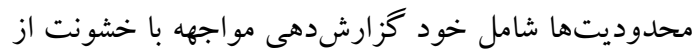

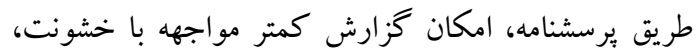

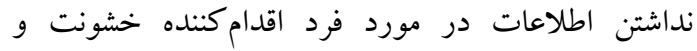
همجينين عدم بررسى خشونت جنسى به دليل مسائل فرهنگى إنى

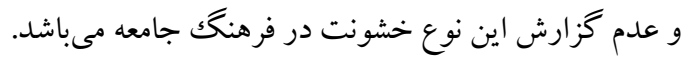

\section{نتيجه كيرى}

نتايج اين مطالعه نشان داد كه ميزان مواجهه يرستاران با بـان خشونت در محل كارشان بالا است و عواملى مانند سن، سابقه كارى، جنسيت و نوع بخش كارى : يرستاران ارتباط

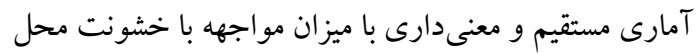

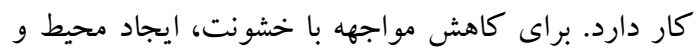

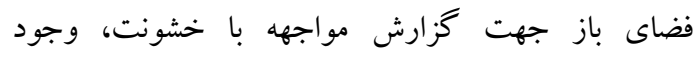
سيستمهايى جهت بيشخيرى و كاهش خشونت در محل كار، بر گزارى دورههاى آموزشى در زمينه برقرارى ارتباط

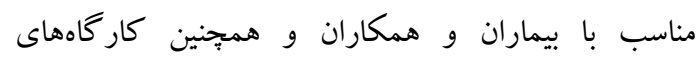

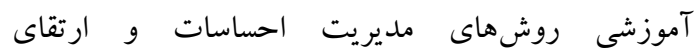

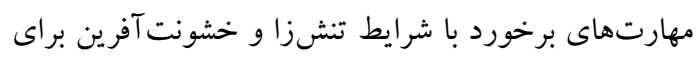

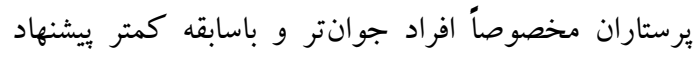

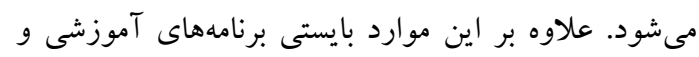




\section{منابع}

1. Lanctôt N, Guay S. The aftermath of workplace violence among healthcare workers: A systematic literature review of the consequences. Aggress Violent Behav. 2014;19(5):492-501.

2. Martinez AJ. Managing Workplace Violence With Evidence-Based Interventions: A Literature Review. J Psychosoc. Nurs Ment Health Serv. 2016;54(9):31-6.

3. Li M, Shu Q, Huang H, Bo W, Wang L, Wu H. Associations of occupational stress, workplace violence and organizational support on chronic fatigue symptoms among nurses. J Adv Nurs. 2020;76(5):1151-61.

4. Occupational Safety and Health Administration (OSHA). Guidelines for preventing workplace violence for healthcare and social service workers. No. 3148-04R, 2015.

5. Kwok RP, Law YK, Li KE, Ng YC, Cheung MH, Fung VK, et al. Prevalence of workplace violence against nurses in Hong Kong. Hong Kong Med J. 2006;12(1):6-9.

6. Lu L, Lok K-I, Zhang L, Hu A, Ungvari GS, Bressington DT, et al. Prevalence of verbal and physical workplace violence against nurses in psychiatric hospitals in China. Arch Psychiatr Nurs. 2019;33(5):68-72.

7. Noorana Zahra A, Feng J-Y. Workplace violence against nurses in Indonesian emergency departments. Enferm Clin. 2018; 28(1):184-90.

8. Celebioglu A, Akpinar RB, Kucukoglu S, Engin R. Violence experienced by Turkish nursing students in clinical settings: their emotions and behaviors. Nurse Educ Today. 2010;30(7):687-91.

9. Cezar ES, Marziale MH. [Occupational violence problems in an emergency hospital in Londrina, Parana, Brazil]. Cad Saude Publica. 2006;22(1):217-21.

10. Samir N, Mohamed R, Moustafa E, Abou Saif H. Nurses' attitudes and reactions to workplace violence in obstetrics and gynaecology departments in Cairo hospitals. East Mediterr Health J. 2012;18(3):198-204.

11. Gunaydin N, Kutlu Y. Experience of Workplace Violence Among Nurses in Health-Care Settings. J Psychiatr Nurs. 2012;3(1):1-5.

12. Dalvand S, Ghanei Gheshlagh R, Najafi F, Zahednezhad H, Sayehmiri K. The Prevalence of Workplace Violence Against Iranian Nurses: A Systematic Review and Meta - Analysis. Shiraz EMed J. 2018;19(9):e65923.

13. Duan X, Ni X, Shi L, Zhang L, Ye Y, Mu H, et al. The impact of workplace violence on job satisfaction, job burnout, and turnover intention: the mediating role of social support. Health Qual Life Outcomes. 2019;17(1):93.

14. Zhao SH, Shi Y, Sun ZN, Xie FZ, Wang JH, Zhang SE, et al. Impact of workplace violence against nurses' thriving at work, job satisfaction and turnover intention: A cross-sectional study. J Clin Nurs. 2018;27(13-14):2620-32.

15. Shoghi M, Sanjari M, Shirazi F, Heidari S, Salemi S, Mirzabeigi G. Workplace Violence and Abuse Against Nurses in Hospitals in Iran. Asian Nurs Res. 2008;2(3):184-93.

16. Budden LM, Birks M, Cant R, Bagley T, Park T. Australian nursing students' experience of bullying and/or harassment during clinical placement. Collegian. 2017;24(2):125-33.

17. Salavati S, Daraie M, Tabesh H, Aradoei Z, Salavati P. Workplace Violence Against Nurses In Ahvaz Educational Hospitals. Nurs Midwifery J. 2015;12(11):1018-27.

18. Jafree SR. Workplace violence against women nurses working in two public sector hospitals of Lahore, Pakistan. Nurs Outlook. 2017;65(4):420-7.

19. Alyaemni A, Alhudaithi $\mathrm{H}$. Workplace violence against nurses in the emergency departments of three hospitals in Riyadh, Saudi Arabia: A cross-sectional survey. NursingPlus Open. 2016;2:35-41.

20. Zhang L, Wang A, Xie X, Zhou Y, Li J, Yang L, et al. Workplace violence against nurses: A cross-sectional study. Int J Nurs Stud. 2017;72:8-14.

21. Al-Omari H. Physical and verbal workplace violence against nurses in Jordan. Int Nurs Rev. 2015;62(1):111-18.

22. Boafo IM. The effects of workplace respect and violence on nurses' job satisfaction in Ghana: a cross-sectional survey. Hum Resour Health. 2018;16(1):99-109.

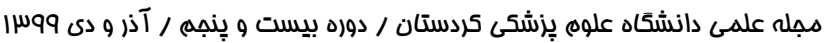


23. Kvas A, Seljak J. Sources of workplace violence against nurses. Work. 2015;52(1):177-84.

24. Liu J, Gan Y, Jiang H, Li L, Dwyer R, Lu K, et al. Prevalence of workplace violence against healthcare workers: a systematic review and meta-analysis. Occup Environ Med. 2019;76(12):927-37.

25. Rafati Rahimzadeh M, Zabihi A, Hosseini S. Verbal and Physical Violence on Nurses in hospitals of Babol University of Medical Sciences. Hayat. 2011;17(2):5-11.

26. World Health Organization(WHO). Workplace Violence in the Health Sector Country Case Studies Research Instruments. 2003.

27. M Albashtawy, Aljezawi M. Emergency nurses' perspective of workplace violence in Jordanian hospitals: A national survey. Int Emerg Nurs. 2016;24:61-5.

28. Babaei N, Rahmani A, Avazeh M, Mohajjelaghdam AR, Zamanzadeh V, Dadashzadeh A. Determine and compare the viewpoints of nurses, patients and their relatives to workplace violence against nurses. J Nurs Manag. 2018;26(5):563-70.

29. Mozafari M, Tavan H. Survey of Violence Against Nursing in The Ilam Training Hospitals at 2012. SJIMU. 2013;21(2):152-60.

30. Speroni KG, Fitch T, Dawson E, Dugan L, Atherton M. Incidence and cost of nurse workplace violence perpetrated by hospital patients or patient visitors. J Emerg Nurs 2014;40(3):218-28.

31. Hahn S, Muller M, Hantikainen V, Kok G, Dassen T, Halfens RJ. Risk factors associated with patient and visitor violence in general hospitals: results of a multiple regression analysis. Int $\mathrm{J}$ Nurs Stud. 2013;50(3):374-85.

32. Zeng JY, An FR, Xiang YT, Qi YK, Ungvari GS, Newhouse R, et al. Frequency and risk factors of workplace violence on psychiatric nurses and its impact on their quality of life in China. Psychiatry Res. 2013;210(2):510-14.

33. Aghajanloo A, Haririan HR, Ghafurifard M. Violence during clinical training among nursing students of Zanjan universities of medical sciences. IJNR. 2010;5(17):47-54.

34. Kitaneh M, Hamdan M. Workplace violence against physicians and nurses in Palestinian public hospitals: a cross-sectional study. BMC Health Serv Res. 2012;12(1):469.

35. Alipour A, Dianat I, Halvani GH, Falah Zadeh H. Individual and job factors affecting the exposure to occupational violence among health care workers in the hospitals in Yazd province in 2016. JHSW. 2018;8(2):175-86.

36.Mahmoudi A. 804 - Contributing factors of workplace violence among nurses at psychiatric and non psychiatric wards. Eur Psychiatry. 2013;28:1. 